\title{
The inhibition of MyD88 and TRIF signaling serve equivalent roles in attenuating myocardial deterioration due to acute severe inflammation
}

\author{
MIN-ZHI OUYANG ${ }^{1 *}$, DAN ZHOU ${ }^{1 *}, Y_{U N} Z^{1 *}$, MING ZHANG $^{1}$ and LING LI $^{2}$ \\ ${ }^{1}$ Department of Ultrasound Diagnosis, The Second Xiangya Hospital of Central South University, Changsha, Hunan 410011; \\ ${ }^{2}$ Medical Basic Teaching Experiment Center, College of Traditional Chinese Medicine, \\ Hunan University of Chinese Medicine, Changsha, Hunan 410208, P.R. China
}

Received February 3, 2017; Accepted October 24, 2017

DOI: $10.3892 /$ ijmm.2017.3239

\begin{abstract}
Myeloid differentiation factor 88 (MyD88) and Toll or interleukin-1 receptor-domain-containing adaptor-inducing interferon- $\beta$ (IFN- $\beta$ ) (TRIF) are two pivotal downstream adaptors of Toll-like receptors. Activation of MyD88 or TRIF signaling in cardiac immune pathology of severe inflammation negatively influences heart function. In the present study, severe septic cardiac injury was induced in C57BL/6 mice by cecum ligation and puncture (CLP). A total of 64 mice were divided randomly into the following four groups ( $\mathrm{n}=16 / \mathrm{group} ; 8$ for observation of survival rate, 8 for heart sample analysis): Sham, CLP, anti-MyD88-CLP and anti-TRIF-CLP. Anti-MyD88 and anti-TRIF antibodies were administered to the respective mice through the tail veins $2 \mathrm{~h}$ before CLP. Measurements of cardiac function, including M-modes, velocity vector imaging and cardiac troponin I, were performed. Myocardial inflammatory cytokines were examined by reverse transcription-polymerase chain reaction (RT-PCR), myocardial neutrophil infiltration was measured by a myeloperoxidase activity assay, intracellular adhesion molecule and vascular cell adhesion molecule mRNA expression levels were investigated, and histopathological characteristics were evaluated. Levels of mRNA transcripts encoding genes for apoptosis production and MyD88, TRIF, nuclear factor- $\kappa \mathrm{B}$ and IFN regulatory factor 3 were investigated by RT-PCR. Mice challenged with CLP demonstrated deleterious cardiac function, increased levels
\end{abstract}

Correspondence to: Dr Ming Zhang, Department of Ultrasound Diagnosis, The Second Xiangya Hospital of Central South University, 139 Renmin Road, Changsha, Hunan 410011, P.R. China E-mail: zm7626@126.com; zm7626@csu.edu.cn

\section{${ }^{*}$ Contributed equally}

Key words: myeloid differentiation factor 88 signaling, Toll or interleukin-1 receptor-domain-containing adaptor-inducing interferon- $\beta$ signaling, severe sepsis, myocardial dysfunction, inflammatory response, apoptosis of interleukin-1 $\beta$ (IL-1 $\beta$ ), IL-6 $\beta$, and tumor necrosis factor- $\alpha$ mRNA, increased neutrophil infiltration, and increased apoptosis. In contrast, mice in the anti-MyD88 CLP and anti-TRIF CLP groups retained cardiac function with reduced cytokine release, decreased neutrophil infiltration, and reduced apoptosis. In addition, there was no significant difference between the anti-MyD88 CLP and anti-TRIF CLP groups. Thus, the present study indicated that MyD88 and TRIF blockades serve notable and equivalent roles in protecting cardiac deterioration from severe sepsis by attenuating cytokine release, reducing neutrophil infiltration and alleviating apoptosis.

\section{Introduction}

Severe sepsis, characterized by an overwhelming systemic immune response to pathogen-associated molecules, such as lipopolysaccharides, may lead to multiple organ failure, shock and even death (1-3). Cardiac impairment, characterized by a reduced ejection fraction and collapsed circulation, is the major consequence of septic shock, and it has been demonstrated to be the greatest risk factor for severe sepsis-associated mortality (4). Severe septic myocardium launches a cascade of overwhelming inflammatory responses, with excessive circulating myocardial depressant factors, as well as overactive neutrophil and macrophage infiltration (5). In addition, increasing evidence indicates that myocardium apoptosis and the inflammatory response lead to lipopolysaccharide-induced cardiac malfunction $(6,7)$, suggesting that anti-apoptosis measures may ameliorate cardiac impairment.

Toll-like receptors (TLRs) are critical pattern-recognition receptors that mediate the innate immune response, and activate signaling networks to promote the inflammatory cascade (8). However, inappropriate and unregulated production of proinflammatory cytokines and mediators results in reduced cardiac output, cardiovascular collapse and mortality $(9,10)$.

There are two major intracellular adaptor proteins that mediate TLR signaling: Myeloid differentiation factor 88 (MyD88) and Toll or interleukin-1 receptor-domaincontaining adaptor-inducing interferon- $\beta$ (IFN- $\beta$ ) (TRIF) (11). All TLRs, except TLR3, are activated via a MyD88-dependent signaling pathway, and subsequently activate cytosolic nuclear 
factor- $\kappa \mathrm{B}(\mathrm{NF}-\kappa \mathrm{B})$, which serves a critical role in host defense and tissue inflammation, and is involved in the pathogenesis of cardiac dysfunction during severe sepsis (12). MyD88 deficiency confers powerful protection against lipopolysaccharide-induced cardiac dysfunction and mortality risk by alleviating cytokine-induced inflammation and reducing neutrophil and macrophage infiltration (13).

TRIF has been demonstrated to be involved in TLR4 and TLR3 signaling, type I IFN regulatory factor-3 (IRF-3) induction, IFN- $\beta$ activation and slower NF- $\kappa \mathrm{B}$ activation. Thus, it regulates the production of various cytokines, including inflammatory cytokines and apoptosis-related inducing factors (14). Systematic deletion of the TRIF gene has been demonstrated to effectively protect mice from endotoxic shock and ischemiareperfusion injury, with improved cardiac function and survival (15). However, few studies have investigated the role and mechanism of TRIF signaling in severe septic myocardium (15-17). Furthermore, the relative contributions of MyD88 and TRIF signaling to the development of cardiac dysfunction in a model of polymicrobial severe sepsis are unknown.

The present study investigated the effect of MyD88- and TRIF-dependent pathways in the TLR-mediated cardiac inflammatory response in a murine model of cecum ligation and puncture (CLP)-induced severe sepsis. The importance of each pathway in influencing myocardial function was also examined. The present study may shed light on a potential useful therapy for sepsis-induced cardiac dysfunction via MyD88 and TRIF blockade.

\section{Materials and methods}

Animal model. A total of 64 male C57/BL6 mice weighing 20-25 g and aged 6-8 weeks were purchased from the Model Animal Research Center of Nanjing University (Nanjing, China) (stock no. J003752). The mice were maintained in a specific pathogen-free environment, with a humidity of $50 \%$, constant temperature of $26^{\circ} \mathrm{C}$, and a 12-h light/dark cycle. The mice had access to food and water ad libitum. All animal care and experimental procedures conformed strictly to the regulations of the Institutional Animal Care and Use Committee of Central South University (Changsha, China). The study protocol was reviewed and approved by the Medical Ethical Committee of the Second Xiangya Hospital of Central South University (Changsha, China). A total of 64 mice were divided randomly into four groups ( $n=16 /$ group; 8 for observation of survival rate, 8 for heart sample analysis): The wild-type (WT)-sham, WT-CLP, anti-MyD88-CLP and anti-TRIF-CLP groups.

Severe sepsis was generated by CLP. Briefly, following anesthetization with $1.5 \%$ pentobarbital sodium $(40 \mathrm{mg} / \mathrm{kg}$; Sigma-Aldrich; Merck KGaA, Darmstadt, Germany) injected intraperitoneally, a $1.0-\mathrm{cm}$ long incision was made on the abdomen of each mouse. The cecum was exposed, ligated below the ileocecal valve with a silk 4-0 suture, and punctured twice with a 20-gauge needle. Anti-MyD88 (5 $\mu \mathrm{l} / \mathrm{g}$; ab2068) and anti-TRIF antibodies (5 $\mu \mathrm{l} / \mathrm{g}$; ab13810) (both from Abcam, Cambridge, UK) were administered to the respective mice through the tail veins $2 \mathrm{~h}$ before CLP. The sham group underwent laparotomy without CLP. Following surgery, pre-warmed normal saline $\left(37^{\circ} \mathrm{C} ; 0.1 \mathrm{ml} / \mathrm{g}\right.$ body weight) was administered subcutaneously to maintain fluid resuscitation and avoid iatrogenic hypothermia. The survival rate of each group was recorded from 12-24 $\mathrm{h}$ after sham operation or CLP.

Echocardiographic assessment of left ventricular (LV) contraction and function. Echocardiography was performed at 6 and $12 \mathrm{~h}$ after CLP under light anesthesia by pentobarbital sodium [40 mg/kg, intraperitoneal (IP)] using an ultrasound scanner (Acuson S3000) coupled with an 18.0-MHz linear transducer (both from Siemens Healthineers, Erlangen, Germany). A single experienced operator who was blinded to the experimental design acquired all images. LV systolic function was assessed by fractional shortening (FS) using the M-mode method at the midpapillary level in the parasternal short-axis view. LV internal diameters at end diastole and end systole were measured. Strain was measured using a speckle tracking approach for the middle of the posterior wall on short-axis views during at least three consecutive heartbeats, and analyzed online using Velocity Vector Imaging software v. 3.5 (Siemens Healthineers). This approach enables rapid and accurate quantitative assessment of global and regional myocardial function (18). Strain was defined as relative deformation of the myocardium (19), which represents myocardial contraction sensitivity, and was expressed as a percentage.

Serum cardiac troponin I (cTnI) measurement. Under anesthesia with pentobarbital sodium $(40 \mathrm{mg} / \mathrm{kg}$, IP), blood samples were collected via puncture from the inferior vena cava by opening the abdomen in all groups $12 \mathrm{~h}$ after CLP. Mice were then sacrificed via cervical dislocation. Blood samples were centrifuged at $589 \mathrm{x} \mathrm{g} / \mathrm{min}$ for $10 \mathrm{~min}$ at $4^{\circ} \mathrm{C}$. The serum cTnI level was measured using an ELISA Quantikine mouse kit (M6000B, MTA00B and MLB00C; R\&D Systems Europe, Ltd., Abingdon, UK) according to the manufacturer's recommendations.

Quantification of $m R N A$ in heart tissue. Following euthanasia, the hearts were harvested and stored at $-80^{\circ} \mathrm{C}$ after being quickly immersed in liquid nitrogen for reverse transcriptionpolymerase chain reaction (RT-PCR) assays. Total RNA was purified from heart tissue using TRIzol reagent (Gibco; Thermo Fisher Scientific, Inc., Waltham, MA, USA) according to the manufacturer's protocol. RT-PCR was performed to amplify mouse interleukin-1 (IL-1), IL-6, tumor necrosis factor- $\alpha$ (TNF- $\alpha)$ and $\beta$-actin mRNA. Using $2 \mu$ l reverse transcriptase (Promega Corp., Madison, WI, USA), reactions were performed in a final volume of $20 \mu \mathrm{l}$ with the gene-specific primers listed in Table I. The expression of the genes examined was normalized to that of $\beta$-actin as an internal control. Amplified PCR products were evaluated by $1.7 \%$ agarose gel electrophoresis and ethidium bromide staining. The integral optical density (IOD) of the electrophoretic bands was quantified. The data presented in the figures was the ratio of the IOD of the target gene to the IOD of the reference gene. Results were interpreted using Image-Pro Plus 6.0 (Media Cybernetics, Inc., Rockville, MD, USA).

Histopathological examination. Samples of hearts were dissected and fixed in $10 \%$ buffered formalin at room temperature for $>48 \mathrm{~h}$, and subsequently embedded in paraffin, cut into $5-\mu \mathrm{m}$ sections, and stained with hematoxylin and eosin 
Table I. Primers used for reverse transcription-polymerase chain reaction.

\begin{tabular}{|c|c|c|}
\hline Gene & Primer & Sequence $\left(5^{\prime}-3^{\prime}\right)$ \\
\hline IL-1 & $\begin{array}{l}\text { Sense } \\
\text { Antisense }\end{array}$ & $\begin{array}{l}\text { GCACTCTGCTTGCTCACCTTTA } \\
\text { GGTCTCTAAGGCCAGAGGTGGA }\end{array}$ \\
\hline IL-6 & $\begin{array}{l}\text { Sense } \\
\text { Antisense }\end{array}$ & $\begin{array}{l}\text { AGTGCGACCTGGACATCCG } \\
\text { TGGCTCTAACAGTCCGCCTAG }\end{array}$ \\
\hline Tumor necrosis factor- $\alpha$ & $\begin{array}{l}\text { Sense } \\
\text { Antisense }\end{array}$ & $\begin{array}{l}\text { AGTGCGACCTGGACATCCG } \\
\text { TGGCTCTAACAGTCCGCCTAG }\end{array}$ \\
\hline$\beta$-actin & $\begin{array}{l}\text { Sense } \\
\text { Antisense }\end{array}$ & $\begin{array}{l}\text { AGTGCGACCTGGACATCCG } \\
\text { TGGCTCTAACAGTCCGCCTAG }\end{array}$ \\
\hline Vascular cell adhesion molecule-1 & $\begin{array}{l}\text { Sense } \\
\text { Antisense }\end{array}$ & $\begin{array}{l}\text { CGGTCATGGTCAAGTGTTTG } \\
\text { GAGATCCAGGGGAATTCA }\end{array}$ \\
\hline Intercellular adhesion molecule-1 & $\begin{array}{l}\text { Sense } \\
\text { Antisense }\end{array}$ & $\begin{array}{l}\text { TATCGGGATGGTGAAGTCT } \\
\text { GGCGGTAATAGGTGTAAATG }\end{array}$ \\
\hline$\beta$-actin & $\begin{array}{l}\text { Sense } \\
\text { Antisense }\end{array}$ & $\begin{array}{l}\text { AGTGCGACCTGGACATCCG } \\
\text { TGGCTCTAACAGTCCGCCTAG }\end{array}$ \\
\hline Interferon & $\begin{array}{l}\text { Sense } \\
\text { Antisense }\end{array}$ & $\begin{array}{l}\text { GGAGCATGGATGTGATCAAG } \\
\text { GAGTTCACTGATGGCTTTGC }\end{array}$ \\
\hline Myeloid differentiation factor 88 & $\begin{array}{l}\text { Sense } \\
\text { Antisense }\end{array}$ & $\begin{array}{l}\text { GGAACAGACCAACTATCGGC } \\
\text { GAGACAACCACTACCATCCG }\end{array}$ \\
\hline $\begin{array}{l}\text { Toll or interleukin- } 1 \text { receptor-domain-containing } \\
\text { adaptor-inducing interferon- } \beta\end{array}$ & $\begin{array}{l}\text { Sense } \\
\text { Antisense }\end{array}$ & $\begin{array}{l}\text { CACCTTCTGCGAGGATTTC } \\
\text { GCTGCTCATCAGAGACTGGT }\end{array}$ \\
\hline Interferon regulatory factor-3 & $\begin{array}{l}\text { Sense } \\
\text { Antisense }\end{array}$ & $\begin{array}{l}\text { TCTGCCCTCAACCGCAAAGAAG } \\
\text { TACTGCCTCCACCATTGGTGTC }\end{array}$ \\
\hline Nuclear factor- $\kappa B$ & $\begin{array}{l}\text { Sense } \\
\text { Antisense }\end{array}$ & $\begin{array}{l}\text { GGGACTACGACCTGAATGCT } \\
\text { GGGCACGGTTGTCAAAGAT }\end{array}$ \\
\hline$\beta$-actin & $\begin{array}{l}\text { Sense } \\
\text { Antisense }\end{array}$ & $\begin{array}{l}\text { TCTGGCACCACACCTTCT } \\
\text { GATCTGGGTCATCTTCTCAC }\end{array}$ \\
\hline
\end{tabular}

IL, interleukin.

at $37^{\circ} \mathrm{C}$ for $15 \mathrm{~min}$. Formalin-fixed, paraffin-embedded heart tissue was deparaffinized and blocked with $2 \%$ bovine serum albumin (Sigma-Aldrich; Merck KGaA) for $30 \mathrm{~min}$ at room temperature. To assess neutrophil accumulation in heart tissue, the sections were incubated with rabbit polyclonal antiGr-1 antibody (1:50; ab25377; Abcam). Macrophages in the myocardium were examined with rabbit polyclonal anti-cluster of differentiation (CD)45 antibody (1:200; ab3638; Abcam). These antibodies were applied for $12 \mathrm{~h}$ at $4^{\circ} \mathrm{C}$. Following this, the secondary antibody (horseradish peroxidase goat anti-rabbit immunoglobulin G; 1:200; G23303; Jackson ImmunoResearch Laboratories, Inc., West Grove, PA, USA) was applied for $50 \mathrm{~min}$ at room temperature. Subsequently, the slides were treated with a 3,3'-diaminobenzidine staining system (Dako; Agilent Technologies, Inc., Santa Clara, CA, USA) according to the manufacturer's protocol. Hematoxylin was used to counterstain the nuclei for $3 \mathrm{~min}$ at room temperature. The slides were observed under a light microscope (Carl Zeiss AG, Oberkochen, Germany) at magnifications of $\mathrm{x} 200$ and $\mathrm{x} 400$.
Myocardial myeloperoxidase (MPO) assay. Tissue MPO activity was determined in the heart. Heart samples were harvested, excised, homogenized, rinsed and dissolved in $60 \mathrm{ml}$ phosphate-buffered saline ( $\mathrm{pH} \mathrm{6}$ ). Subsequently, $0.9 \mathrm{ml}$ tissue homogenate was mixed well with $0.1 \mathrm{ml}$ myocardial MPO (Nanjing Jiancheng Bioengineering Institute, Nanjing, China) and activity was assayed using a MPO Colorimetric activity assay kit (Nanjing Jiancheng Bioengineering Institute). After resting at $37^{\circ} \mathrm{C}$ in a water bath for $15 \mathrm{~min}$, the mixture was added to color carrier and $\mathrm{H}_{2} \mathrm{O}_{2}$. Following this, the mixture was incubated at $60^{\circ} \mathrm{C}$ for $10 \mathrm{~min}$ in a water bath, and the rate of change in absorbance at $460 \mathrm{~nm}$ was measured using a spectrophotometer (CE 9000; Cecil Instruments, Ltd., Cambridge, UK). Myocardial MPO activity was expressed as $\mathrm{U} / 1$ protein in wet tissue.

In situ apoptosis assay. Apoptosis assays, including those conducted to detect caspase-3 and Fas/Fas ligand (FasL) activity, were performed using the RT-PCR method described above. The primers used are listed in Table II. 
Table II. Primers used for myocardial apoptosis assays.

\begin{tabular}{|c|c|c|}
\hline Gene & Primer & Sequence (5'-3') \\
\hline \multirow[t]{2}{*}{ Fas } & Sense & CCGCAGGCTGCCCACACAGG \\
\hline & Antisense & CTACCTTAGTGACCTTTTCA \\
\hline \multirow[t]{2}{*}{ Fas ligand } & Sense & AGAACTCCGTGAGCCAAC \\
\hline & Antisense & TGTGTCTTCCCATTCCAG \\
\hline \multirow[t]{2}{*}{ Caspase-3 } & Sense & GGGATGAAAGCGCAGTGTCCTGC \\
\hline & Antisense & AGACTCCGGCAGTAGTCGCCTC \\
\hline \multirow[t]{2}{*}{$\beta$-actin } & Sense & TCTGGCACCACACCTTCT \\
\hline & Antisense & GATCTGGGTCATCTTCTCAC \\
\hline
\end{tabular}

Statistical analysis. Statistical analysis was performed using GraphPad Prism 5.0 software (GraphPad Software, Inc., La Jolla, CA, USA). All data were presented as the mean \pm standard deviation. Comparison among groups was performed using one-way analysis of variance with Bonferroni post hoc tests for statistical significance. Survival rates were estimated using the log-rank test. $\mathrm{P}<0.05$ was considered to indicate a statistically significant difference.

\section{Results}

Survival rate during severe sepsis is lower in WT-CLP mice than in anti-MyD88 and anti-TRIF mice. A total of $12 \mathrm{~h}$ after CLP, WT-CLP mice displayed septic symptoms, including ruffled hair, slow physical actions, shivering and low temperature. The survival rate at $16 \mathrm{~h}$ was $20 \%$. Mice in the anti-MyD88-CLP and anti-TRIF-CLP groups presented signs of moderate health, such as shiny hair, and normal physical actions and temperature throughout the observation period. The survival rates at $16 \mathrm{~h}$ were $100 \%$ and at $24 \mathrm{~h}$ in these groups were 50 and $37 \%$, respectively, which was significantly higher than that in the WT-CLP group $(\mathrm{P}<0.05)$. These results indicate that MyD88 and TRIF signaling contributed to the severe sepsis-linked high mortality rate observed in WT-CLP mice (Fig. 1).

Cardiac function is better in mice in the anti-MyD88 and anti-TRIF groups than in mice in the WT group following CLP. M-mode studies indicated that baseline LV contractile function was similar in the four experimental groups. CLP resulted in significantly deteriorated $\mathrm{LV}$ function, as evidenced by 20 and $40 \%$ reductions in strain at 6 and $12 \mathrm{~h}$ after CLP, respectively, compared with the baseline measurements (WT-CLP vs. WT-sham: 6 h post-CLP, 16.6 vs. 20.3\%, $\mathrm{P}<0.05$; $12 \mathrm{~h}$ post-CLP, 12.5 vs. $19.3 \%, \mathrm{P}<0.01$ ) (Table III). In addition, compared with the baseline, the WT-CLP group demonstrated reductions in FS of $21 \%$ at $12 \mathrm{~h}$ after CLP $(41$ vs. $52 \%, \mathrm{P}<0.05)$ and $50 \%$ at $24 \mathrm{~h}$ after CLP (27 vs. 52\%, P<0.01) (Table III). The anti-MyD88- and anti-TRIF-CLP groups conserved LV contractile function, as demonstrated by significantly higher global longitudinal strain compared with that in the WT-CLP group at each time-point (all P<0.05) (Table III), as well as improved FS at $24 \mathrm{~h}$ after CLP (anti-MyD88- and anti-TRIF-CLP vs. WT-CLP: 38 and 42 vs. 27\%, P<0.05) and

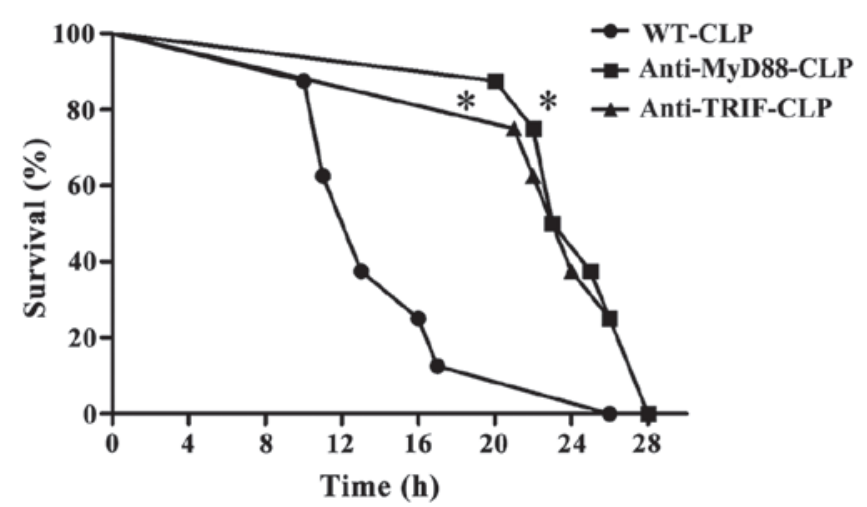

Figure 1. Mice in the anti-MyD88 and anti-TRIF groups exhibit a higher survival rate than WT mice following a CLP procedure. Survival rates were recorded from $8 \mathrm{~h}$ after induction of CLP until the survival rate reached $0 \% . \mathrm{n}=8 /$ group. ${ }^{*} \mathrm{P}<0.05$ vs. WT-CLP at 16, 20 and $24 \mathrm{~h}$. MyD88, myeloid differentiation factor 88; TRIF, Toll or interleukin-1 receptor-domain-containing adaptorinducing interferon- $\beta$; CLP, cecum ligation and puncture; WT, wild-type.

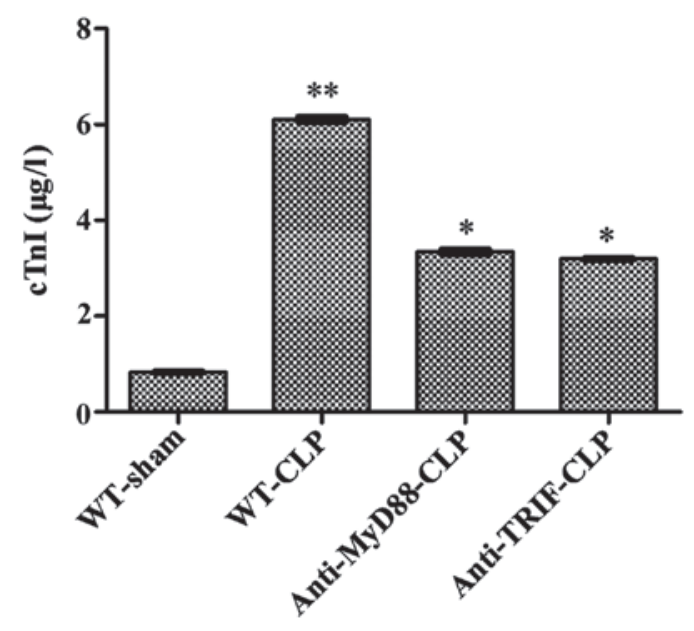

Figure 2. Mice in the anti-MyD88- and anti-TRIF-CLP groups exhibit less cardiac injury compared with WT-CLP mice during severe sepsis. $n=8$ /group; ${ }^{* *} \mathrm{P}<0.05$ vs. WT-sham; ${ }^{*} \mathrm{P}<0.05$ vs. WT-CLP. MyD88, myeloid differentiation factor 88; TRIF, Toll or interleukin-1 receptor-domain-containing adaptorinducing interferon- $\beta$; CLP, cecum ligation and puncture; WT, wild-type; cTnI, cardiac troponin I.

smaller LV internal diameters at end systole at $24 \mathrm{~h}$ (anti-MyD88and anti-TRIF-CLP vs. WT-CLP: 1.8 and 1.73 vs. $2.3 \mathrm{~mm}$, $\mathrm{P}<0.05$ ) (Table III).

The circulating level of cTnI in WT-CLP mice was six times higher than that in WT-sham mice $(6.12 \pm 0.22 \mathrm{vs} .0 .84 \pm 0.06 \mu \mathrm{g} / 1$, respectively, $\mathrm{P}<0.05)$, and approximately two times higher than those in anti-MyD88-CLP and anti-TRIF-CLP mice $(6.12 \pm 0.22$ vs. $3.34 \pm 0.11$ and $3.19 \pm 0.14 \mu \mathrm{g} / 1$, respectively, $\mathrm{P}<0.05)$, with no significant difference between the latter two groups. These results further demonstrate that mice treated with anti-MyD88 and anti-TRIF antibodies exhibited less severe sepsis-induced cardiac injury than mice in the WT-CLP group (Fig. 2).

Anti-MyD88 and anti-TRIF antibodies have critical effects on the inhibition of myocardial inflammatory cytokines following $C L P$. After $24 \mathrm{~h}$, CLP induced a significant increase in myocardial IL-1, IL-6 and TNF- $\alpha$ mRNA production compared with 
Table III. Serial echocardiographic measurements before and after CLP in the different experimental groups.

\begin{tabular}{|c|c|c|c|c|}
\hline \multirow[b]{2}{*}{ Measurement in each group } & \multicolumn{4}{|c|}{ Time-point } \\
\hline & Baseline & $6 \mathrm{~h}$ & $12 \mathrm{~h}$ & $24 \mathrm{~h}$ \\
\hline \multicolumn{5}{|l|}{ Heart rate (bpm) } \\
\hline WT-sham & $611.0 \pm 9.0$ & $612.0 \pm 12.0$ & $622.0 \pm 13.0$ & $588.0 \pm 12.0$ \\
\hline WT-CLP & $601.0 \pm 14.0$ & $562.0 \pm 19.0$ & $493.0 \pm 25.0$ & $432.0 \pm 30.0$ \\
\hline Anti-MyD88-CLP & $598.0 \pm 11.0$ & $611.0 \pm 14.0$ & $558.0 \pm 15.0$ & $500.0 \pm 24.0$ \\
\hline Anti-TRIF-CLP & $604.0 \pm 10.0$ & $610.0 \pm 14.0$ & $562.0 \pm 19.0$ & $502.0 \pm 26.0$ \\
\hline \multicolumn{5}{|l|}{ Blood pressure (mmHg) } \\
\hline WT-sham & $84.0 \pm 2.0$ & $84.0 \pm 2.0$ & $83.7 \pm 3.0$ & $83.0 \pm 3.2$ \\
\hline WT-CLP & $94.0 \pm 3.2$ & $72.0 \pm 4.3^{\mathrm{a}}$ & $55.0 \pm 6.8^{b}$ & $37.0 \pm 6.0^{\mathrm{b}}$ \\
\hline Anti-MyD88-CLP & $88.0 \pm 2.2$ & $80.3 \pm 3.0^{\mathrm{a}}$ & $71.0 \pm 4.5^{\mathrm{a}, \mathrm{c}}$ & $60.0 \pm 6.1^{\mathrm{b}, \mathrm{c}}$ \\
\hline Anti-TRIF-CLP & $89.0 \pm 2.3$ & $84.0 \pm 2.7$ & $73.0 \pm 3.6^{\mathrm{a}, \mathrm{c}}$ & $62.0 \pm 6.8^{\mathrm{b}, \mathrm{c}}$ \\
\hline \multicolumn{5}{|l|}{ LVIDd (mm) } \\
\hline WT-sham & $3.0 \pm 0.1$ & $3.0 \pm 0.0$ & $2.9 \pm 0.1$ & $3.0 \pm 0.1$ \\
\hline WT-CLP & $3.2 \pm 0.1$ & $3.3 \pm 0.1$ & $3.5 \pm 0.1^{\mathrm{a}}$ & $3.8 \pm 0.1^{\mathrm{a}}$ \\
\hline Anti-MyD88-CLP & $3.0 \pm 0.1$ & $3.1 \pm 0.1$ & $3.1 \pm 0.2^{\mathrm{c}}$ & $3.5 \pm 0.1^{\mathrm{a}, \mathrm{c}}$ \\
\hline Anti-TRIF-CLP & $3.1 \pm 0.1$ & $3.2 \pm 0.1$ & $3.2 \pm 0.2$ & $3.4 \pm 0.1$ \\
\hline \multicolumn{5}{|l|}{ LVIDs (mm) } \\
\hline WT-sham & $1.5 \pm 0.0$ & $1.6 \pm 0.1$ & $1.5 \pm 0.0$ & $1.5 \pm 0.1$ \\
\hline WT-CLP & $1.5 \pm 0.1$ & $1.5 \pm 0.1^{\mathrm{a}}$ & $1.9 \pm 0.1^{\mathrm{a}}$ & $2.3 \pm 0.1^{\mathrm{b}}$ \\
\hline Anti-MyD88-CLP & $1.4 \pm 0.1$ & $1.4 \pm 0.1$ & $1.6 \pm 0.1$ & $1.8 \pm 0.1^{\mathrm{a}, \mathrm{c}}$ \\
\hline Anti-TRIF-CLP & $1.4 \pm 0.1$ & $1.4 \pm 0.1$ & $1.5 \pm 0.1$ & $1.7 \pm 0.1^{\mathrm{a}, \mathrm{c}}$ \\
\hline \multicolumn{5}{|l|}{ Fractional shortening (\%) } \\
\hline WT-sham & $50.0 \pm 2.1$ & $47.0 \pm 1.3$ & $49.0 \pm 1.6$ & $50.0 \pm 2.0$ \\
\hline WT-CLP & $52.0 \pm 3.0$ & $51.0 \pm 1.6$ & $41.0 \pm 1.9^{\mathrm{a}}$ & $27.0 \pm 2.2^{\mathrm{b}}$ \\
\hline Anti-MyD88-CLP & $53.0 \pm 2.2$ & $53.0 \pm 1.8$ & $50.0 \pm 2.0^{c}$ & $38.0 \pm 2.2^{\mathrm{a}, \mathrm{c}}$ \\
\hline Anti-TRIF-CLP & $53.0 \pm 1.7$ & $52.0 \pm 2.0$ & $50.0 \pm 1.8^{c}$ & $42.0 \pm 1.9^{\mathrm{a}, \mathrm{c}}$ \\
\hline \multicolumn{5}{|l|}{ Strain } \\
\hline WT-sham & $19.6 \pm 1.7$ & $20.3 \pm 2.0$ & $19.3 \pm 2.4$ & $19.1 \pm 2.1$ \\
\hline WT-CLP & $20.3 \pm 2.2$ & $16.6 \pm 1.7^{\mathrm{a}, \mathrm{d}}$ & $12.5 \pm 2.0^{\mathrm{b}, \mathrm{e}}$ & $10.4 \pm 2.0^{\mathrm{b}}$ \\
\hline Anti-MyD88-CLP & $20.4 \pm 2.2$ & $18.8 \pm 2.1^{\mathrm{c}}$ & $17.2 \pm 2.4^{\mathrm{a}, \mathrm{c}}$ & $15.3 \pm 1.4^{\mathrm{a}, \mathrm{c}}$ \\
\hline Anti-TRIF-CLP & $19.8 \pm 2.4$ & $18.7 \pm 2.2^{\mathrm{c}}$ & $17.6 \pm 2.5^{\mathrm{a}, \mathrm{c}}$ & $15.6 \pm 1.8^{\mathrm{a}, \mathrm{c}}$ \\
\hline
\end{tabular}

the levels observed in the WT-sham group $(\mathrm{P}<0.05)$ (Fig. 3). These levels were similar in the anti-MyD88-CLP, antiTRIF-CLP and WT-sham groups, and significantly lower than the levels in the WT-CLP group $(\mathrm{P}<0.05)$. Production was slightly, but not significantly, higher in the anti-MyD88 CLP group than in the anti-TRIF CLP group.

MyD88 and TRIF have equivalent effects on neutrophil infiltration following CLP. Following CLP, the myocardial MPO activity level was significantly higher in mice of the WT-CLP group than the level in WT-sham mice (73 vs. $49 \mu / 1$, respectively, $\mathrm{P}<0.05$ ) (Fig. 4). In contrast, MPO activity levels were significantly reduced in the anti-MyD88-CLP and
anti-TRIF-CLP groups compared to the level in the WT-CLP group (62 and 59 vs. $73 \mu / 1$, respectively, $\mathrm{P}<0.05$ ) (Fig. 4). No significant difference was observed between the anti-MyD88 and anti-TRIF antibody groups, indicating that these antibodies had equivalent effects on alleviating neutrophil infiltration.

Increased expression of adherent molecules in heart tissue, including vascular cell adhesion molecule-1 (VCAM-1) and intracellular adhesion molecule-1 (ICAM-1), was observed in the WT-CLP group compared with the WT-sham group $(\mathrm{P}<0.05)$ (Fig. 5). The levels of VCAM-1 and ICAM-1 mRNA were significantly lower in the anti-MyD88-CLP and anti-TRIF-CLP groups than the levels in the WT-CLP group $(\mathrm{P}<0.05)$ (Fig. 5). 
A
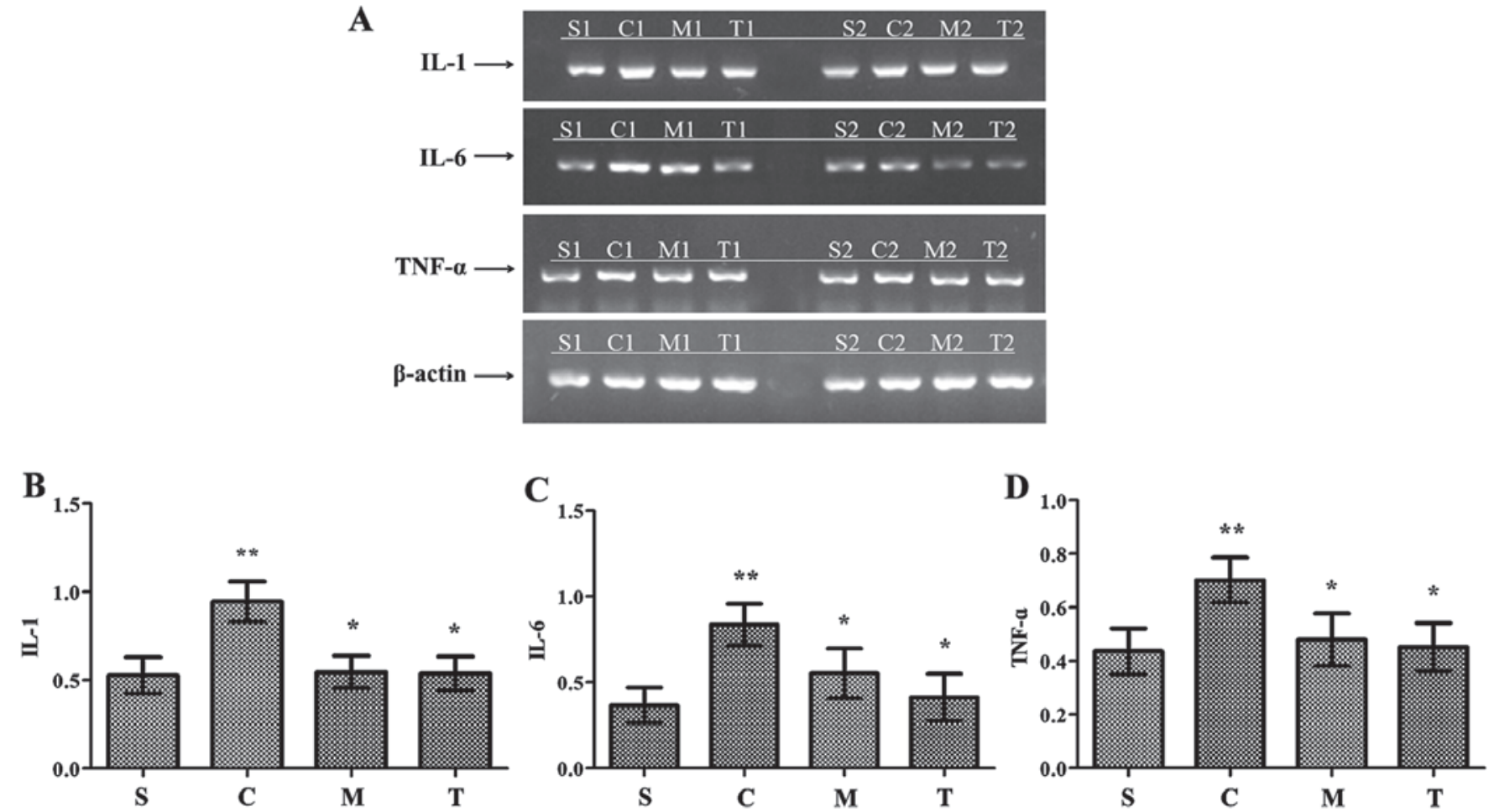

Figure 3. Myocardial inflammatory cytokines are reduced by anti-MyD88 and anti-TRIF antibody treatments following CLP. (A) Reverse transcription-polymerase reaction results for inflammatory cytokine expression levels in each group. Expression levels of (B) IL-1, (C) IL-6 and (D) TNF- $\alpha$ were decreased in the anti-MyD88- and anti-TRIF-CLP groups compared with the levels in the WT-CLP group. n=8/group. ${ }^{* *} \mathrm{P}<0.05$ vs. S; ${ }^{*}<0.05$ vs. C. S, WT-sham group; C, WT-CLP group; M, anti-MyD88-CLP group; T, anti-TRIF-CLP group; MyD88, myeloid differentiation factor 88; TRIF, Toll or interleukin-1 receptor-domain-containing adaptor-inducing interferon- $\beta$; CLP, cecum ligation and puncture; WT, wild-type; IL, interleukin; TNF- $\alpha$, tumor necrosis factor- $\alpha$.

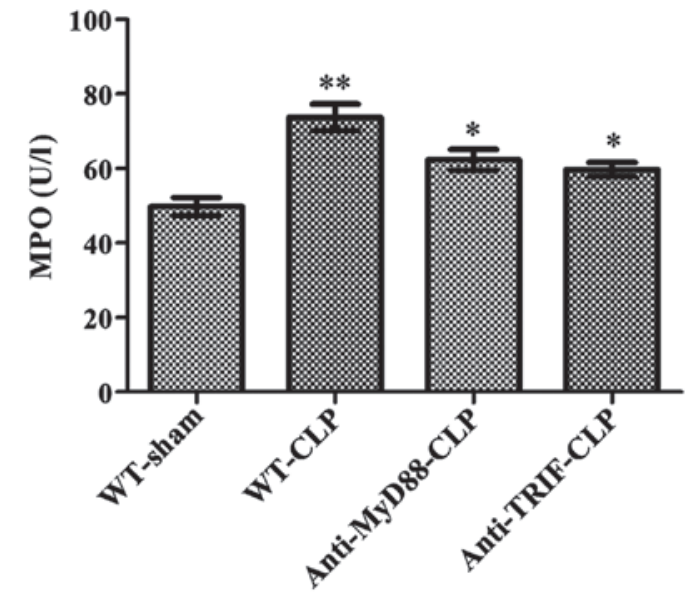

Figure 4. Anti-MyD88 and anti-TRIF antibody treatments inhibit neutrophil filtration into the myocardium following CLP, according to MPO levels. $\mathrm{n}=8$ /group. ${ }^{* *} \mathrm{P}<0.05$ vs. WT-sham; ${ }^{*} \mathrm{P}<0.05$ vs. WT-CLP. MyD88, myeloid differentiation factor 88; TRIF, Toll or interleukin-1 receptor-domain-containing adaptor-inducing interferon- $\beta$; CLP, cecum ligation and puncture; WT, wild-type; MPO, myeloperoxidase.

Anti-MyD88 and anti-TRIF treatments improve myocardial structure and reduce neutrophil and macrophage infiltration during severe sepsis. In the WT-sham group, myocardial fibers were arranged regularly, with distinct striation and no apparent degeneration or necrosis. In the WT-CLP group, edema, local swelling and some myocardial necrosis with disorganized myocardial fibers were evident in the center of reperfusion (Fig. 6).
Neutrophil and macrophage infiltration, demonstrated by a pervasive brown-yellow color in cardiac muscle cells, was observed in myocardial tissue samples from the WT-CLP, anti-MyD88-CLP and anti-TRIF-CLP groups. Consistent with the myocardial MPO results, the areas of neutrophil and macrophage infiltration in myocardial tissue samples from mice in the WT-CLP group were larger than in those from WT-sham mice. This expression in the anti-MyD88-CLP and anti-TRIF-CLP groups did not differ from that in the WT-sham group, and was notably lower than that in the WT-CLP group (Fig. 6).

Anti-MyD88 and anti-TRIF antibodies attenuate myocardial apoptosis in severe sepsis. Fas/FasL mRNA levels were significantly increased in hearts from mice of the WT-CLP group compared with the levels in the WT-sham group $(\mathrm{P}<0.05)$. Furthermore, compared to WT-CLP mice, the levels were significantly lower in the hearts of mice in the anti-TRIF-and anti-MyD88-CLP groups ( $\mathrm{P}<0.05)$ (Fig. 7). Notably, the level of caspase-3 activity was slightly, yet significantly, higher in WT-CLP mice than in mice of the anti-TRIF- and anti-MyD88CLP groups $(\mathrm{P}<0.05)$ (Fig. 7).

MyD88, TRIF, NF- $\mathrm{kB}$ and IRF-3 expression was significantly higher in the WT-CLP group than in the WT-sham group $(\mathrm{P}<0.05)$ (Fig. 8). These levels were also significantly higher in the WT-CLP group than in the anti-MyD88- and anti-TRIF-CLP groups $(\mathrm{P}<0.05)$ (Fig. 8). These results suggest that: i) MyD88 and TRIF promote cardiac injury during severe sepsis; ii) MyD88 is a key adaptor protein in the TLR-mediated MyD88-dependent NF- $\mathrm{kB}$ activation pathway, 
A

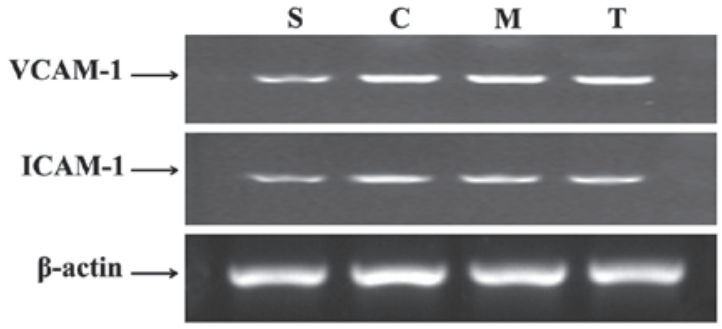

B

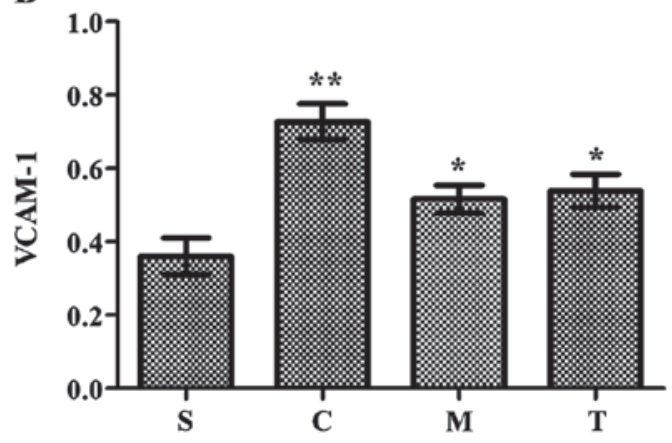

C

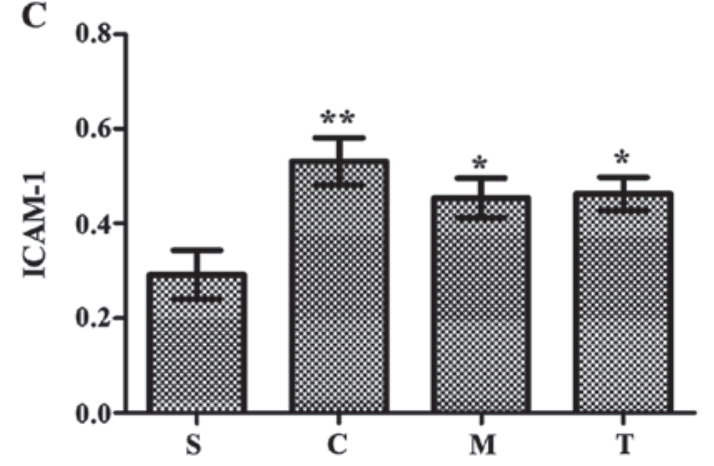

Figure 5. Anti-MyD88 and anti-TRIF antibody treatments inhibit the expression of VCAM-1 and ICAM-1. (A) Reverse transcription-polymerase chain reaction results and semi-quantitative analysis of (B) VCAM-1 and (C) ICAM-1 mRNA expression levels. n=8/group. ${ }^{* *} \mathrm{P}<0.05$ vs. S; ${ }^{*} \mathrm{P}<0.05$ vs. C. S, WT-sham group; C, WT-CLP group; M, anti-MyD88-CLP group; T, anti-TRIF-CLP group; MyD88, myeloid differentiation factor 88; TRIF, Toll or interleukin-1 receptor-domain-containing adaptor-inducing interferon- $\beta$; CLP, cecum ligation and puncture; WT, wild-type; VCAM-1, vascular cell adhesion molecule-1; ICAM-1, intercellular adhesion molecule-1.
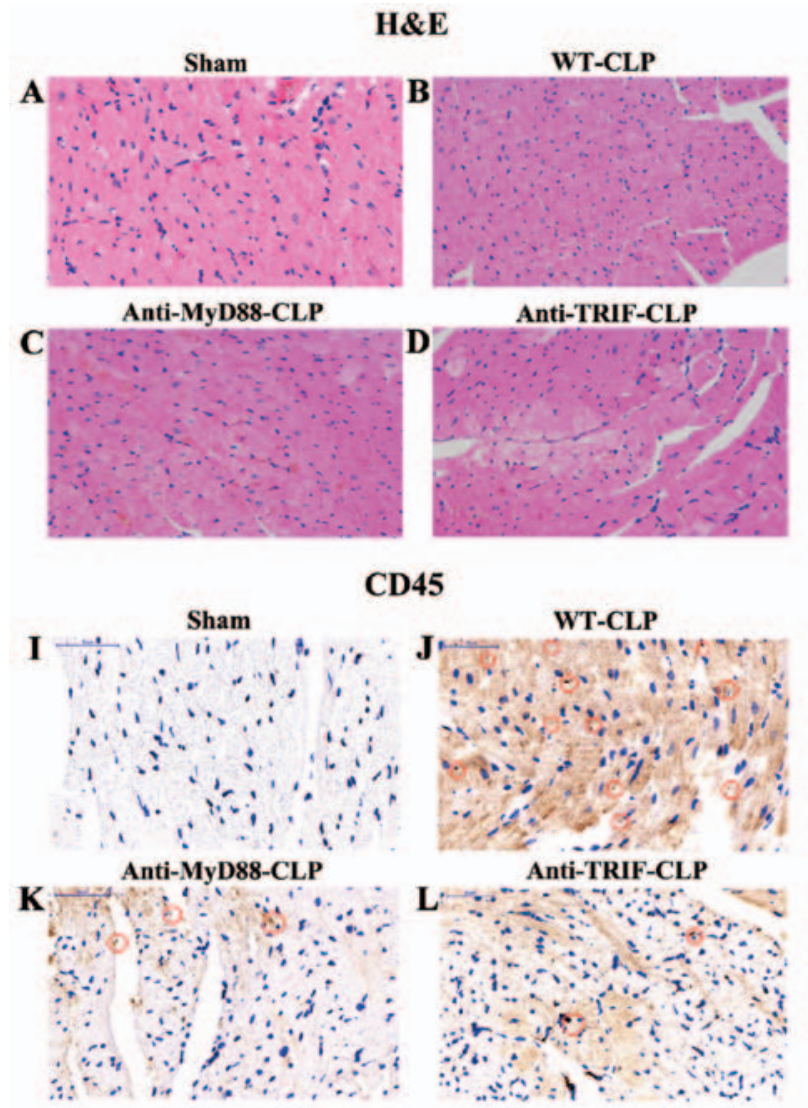

H\&E

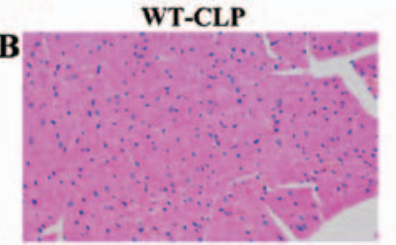

\section{CD45}

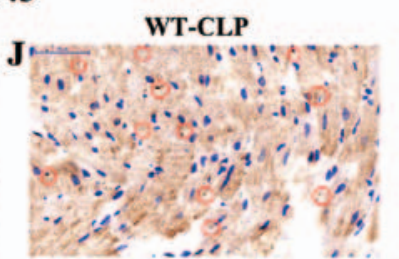
Anti-TRIF-CLP

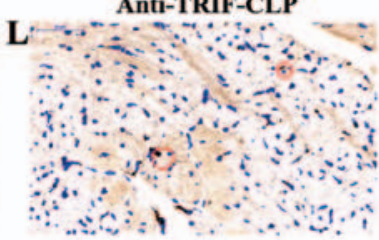

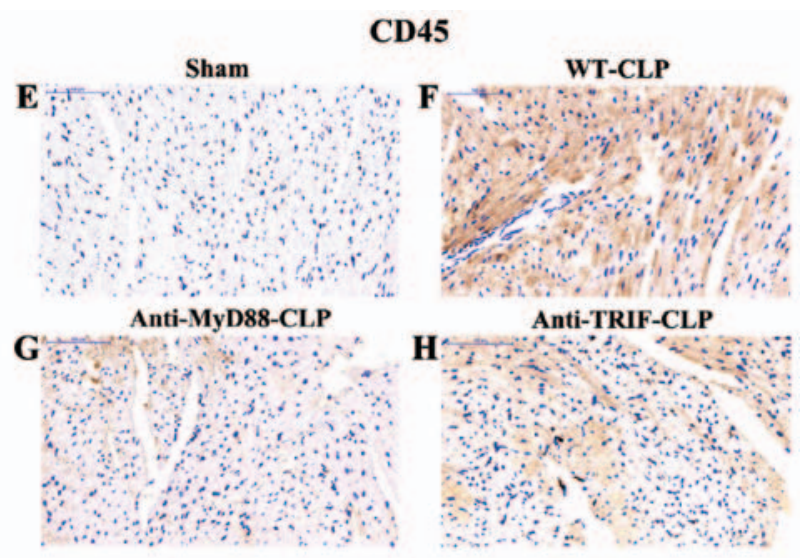

Gr-1

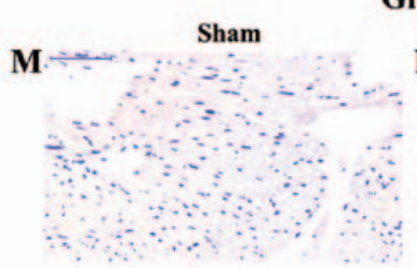

Anti-MyD88-CLP

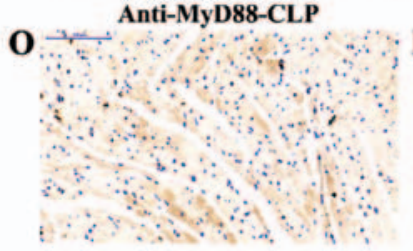

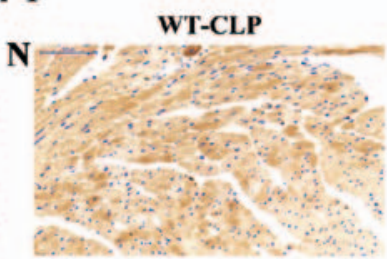

Anti-TRIF-CLP

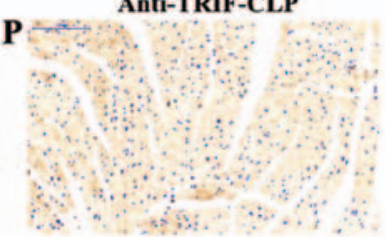

Figure 6. Anti-MyD88 and anti-TRIF treatments reduce myocardial injury and neutrophil infiltration in mice with severe sepsis after 24 h. (A-D) H\&E staining demonstrated moderate edema, local swelling, and some myocardial necrosis along with disorganized myocardial fibers in mice in the WT-CLP group (magnification, x200). (E-L) Incubation with anti-CD45 antibody indicated that there were increased neutrophils (brown staining) in the hearts of mice in the WT-CLP group compared to the levels in the hearts of mice in the anti-MyD88- and anti-TRIF-CLP groups [(E-H) magnification, x200; (I-L) magnification, x400)]. Red circles indicate CD45-positive cardiomyocytes, stained in brown. (M-P) Incubation with anti-rabbit polyclonal anti-Gr-1 antibody indicated that there were increased macrophages (brown staining) in the hearts of mice in the WT-CLP group compared to the levels in the hearts of mice in the anti-MyD88- and anti-TRIF-CLP groups [(M-P) magnification, x200]. MyD88, myeloid differentiation factor 88; TRIF, Toll or interleukin-1 receptor-domain-containing adaptor-inducing interferon- $\beta$; CLP, cecum ligation and puncture; WT, wild-type; H\&E, hematoxylin and eosin; CD45, cluster of differentiation 45. 


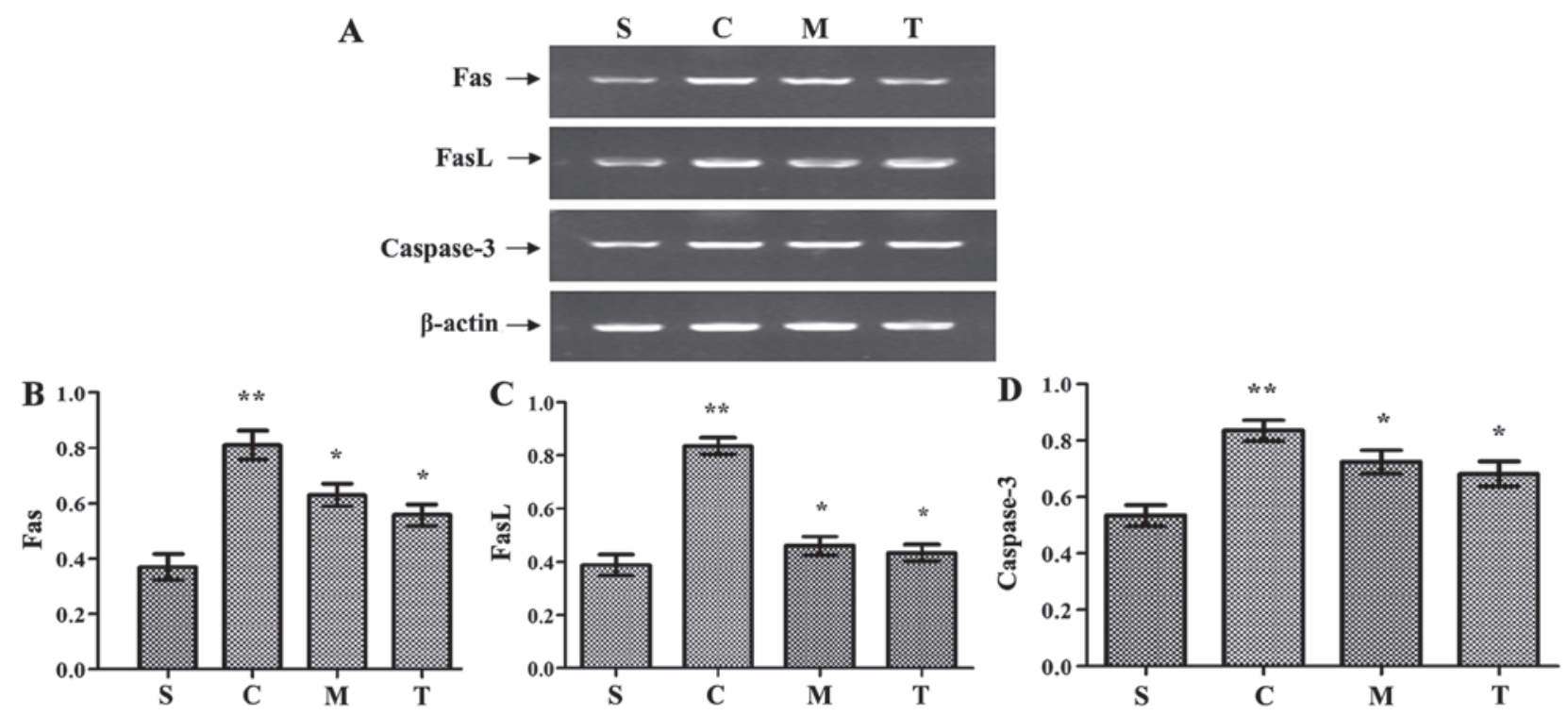

Figure 7. Inhibition of MyD88 and TRIF reduces the expression of apoptosis cytokines, including Fas, FasL and caspase-3, following CLP. (A) FAS, FASL and caspase-3 expression was detected by reverse transcription-polymerase chain reaction. Semi-quantitative analysis of (B) FAS, (C) FASL and (D) caspase-3 expression. $n=8$ /group. ${ }^{* *} \mathrm{P}<0.05$ vs. $\mathrm{S} ;$ " $^{\mathrm{P}}<0.05$ vs. C. $\mathrm{S}$, WT-sham group; $\mathrm{C}$, WT-CLP group; M, anti-MyD88-CLP group; T, anti-TRIF-CLP group; MyD88, myeloid differentiation factor 88 ; TRIF, Toll or interleukin-1 receptor-domain-containing adaptor-inducing interferon- $\beta$; CLP, cecum ligation and puncture; WT, wild-type; FasL, Fas ligand.
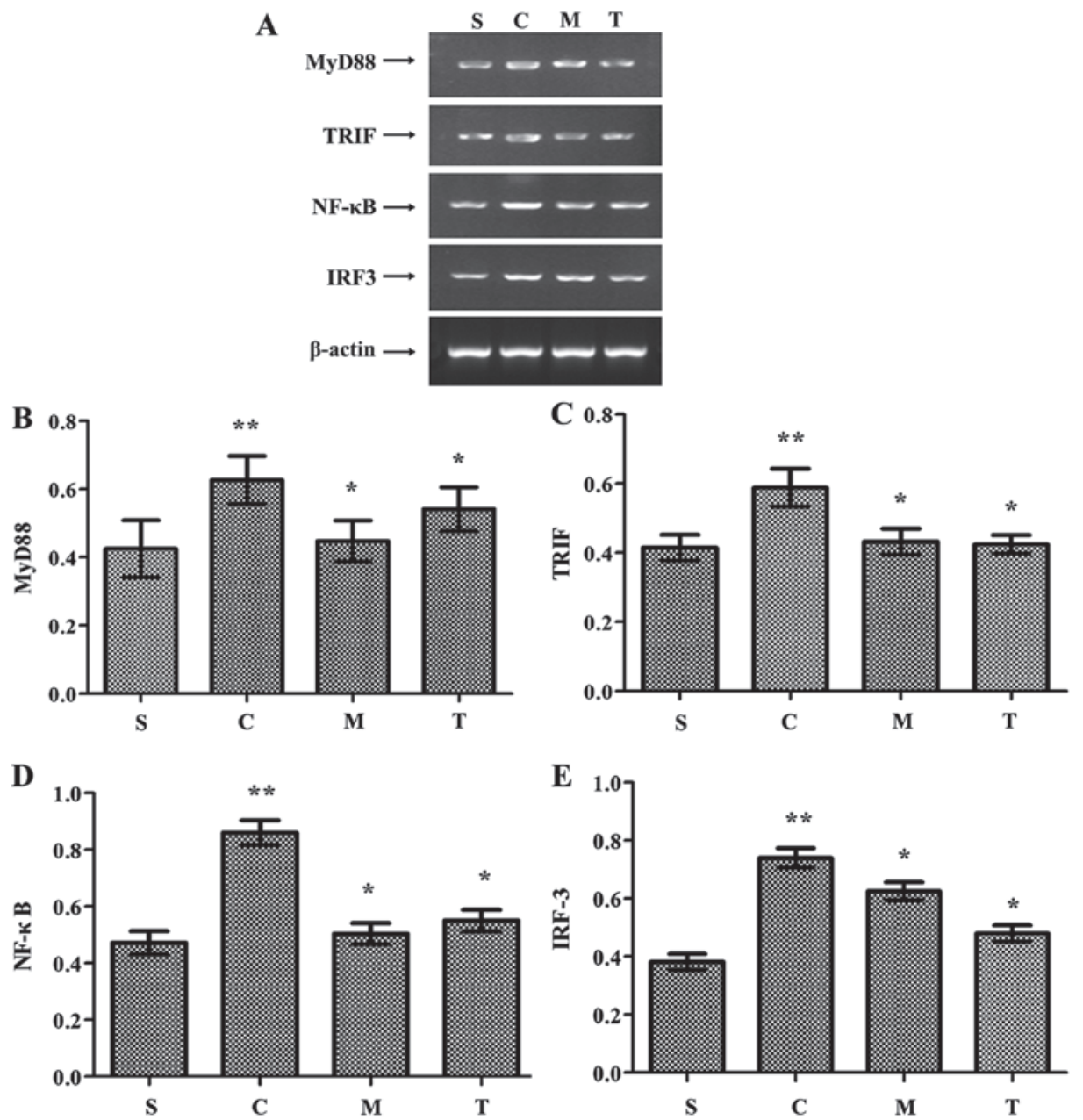

Figure 8. Inhibition of MyD88 and TRIF reduces the expression of MyD88, TRIF, NF-kB and IRF-3 in the myocardium following CLP. (A) MyD88, TRIF, NF- $\mathrm{KB}$ and IRF-3 expression detected by reverse transcription polymerase chain reaction. Semi-quantitative analysis of (B) MyD88, (C) TRIF, (D) NF- $\mathrm{KB}$ and (E) IRF-3 expression. "** $\mathrm{P}<0.05$ vs. S; "P<0.05 vs. C. S, WT-sham group; C, WT-CLP group; M, anti-MyD88-CLP group; T, anti-TRIF-CLP group; MyD88, myeloid differentiation factor 88; TRIF, Toll or interleukin-1 receptor-domain-containing adaptor-inducing interferon- $\beta$; CLP, cecum ligation and puncture;

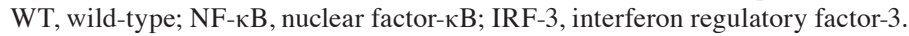


and TRIF is a key adaptor protein in the TLR-mediated MyD88-independent pathway; and iii) TLR domain alignment of the MyD88-dependent and TRIF-dependent pathways serves an essential role in impairment of cardiac function during severe sepsis.

\section{Discussion}

Clinical and experimental studies have demonstrated that inflammatory cardiomyopathy, frequently due to infection-triggered myocarditis, is an early and fatal complication of septic shock (20). The pathogenesis of myocardial injury is predominantly due to uncontrolled inflammatory responses, including excessive secretion of inflammatory cytokines and robust neutrophil and macrophage infiltration $(20,21)$. Activated neutrophils react with inflammatory cytokines, disrupt the blood vessel endothelium, promote platelet aggregation and adhesion to endothelium, and block blood flow, consequently leading to cardiac dysfunction (21).

The present study demonstrated that the two major downstream signaling pathways of TLRs, the MyD88- and TRIF-dependent pathways, serve important roles in sepsisinduced cardiac injury following CLP. The present study also indicated that MyD88 and TRIF inhibition have a protective effect on cardiac function during sepsis. TLRs have been demonstrated to be important in these pathological processes (10). MyD88 is one of the adaptor proteins of TLRs, which holds a key position in the cascade of inflammatory promotion. MyD88 blockade could decrease IL-1 $\beta$, IL- $6 \beta$ and TNF- $\alpha$ mRNA levels and modulate circulating neutrophil and macrophage recruitment to protect myocardial dysfunction $(22,23)$. ICAM-1 and VCAM-1 are known to be adhesion factors, inducing neutrophil and macrophage infiltration of the myocardium during septic shock (24). The present study indicated significantly decreased myocardial MPO levels, and ICAM and VCAM expression, as well as reduced neutrophil and macrophage accumulation in mice in the anti-MyD88-CLP group. These results suggest that MyD88 promotes neutrophil and macrophage recruitment, adhesion to the endothelium, and blockage of blood flow, resulting in myocardial injury. These observations indicate that MyD88 signaling serves a critical role in the impairment of cardiac function.

The TRIF-dependent signaling pathway leads to the activation of IRF-3 and induction of IFN- $\beta$, activating NF- $\kappa$ B and inducing the synthesis and release of inflammatory cytokines, representing the major host immune mechanism (14). It has been reported by Feng et al (25) that TRIF signaling was implicated in the aggravation of the inflammatory response and high mortality caused by endotoxic shock; however, lack of TRIF did not change cardiac impairment in polymicrobial peritoneal sepsis. We speculate that this difference may be attributed to the different animal models used in the study. Another study demonstrated that TRIF signaling has a critical role in protection against ischemia-reperfusion-induced myocarditis by maintaining LV function and reducing myocardial ischemia size (14). However, the authors argued that the mechanism by which TRIF signaling mediates cardiac impairment was independent of the inflammatory response, as deletion of TRIF did not activate neutrophil recruitment or cardiac cytokine secretion (15). The present data indicated that TRIF blockade alleviates inflammatory cytokine secretion, and neutrophil and macrophage recruitment, thereby maintaining myocardial function. Consistently, TRIF-deficient mice had a limited capacity to establish an immune response, accompanied by decreased neutrophil infiltration and minimized requirement for a systemic inflammatory response during viral myocarditis and bacterial sepsis (26). We infer that the difference between TRIF signaling activation in ischemia-reperfusion and the TLR4-TRIF pathway in the present study was due to the different pathophysiology mechanism between ischemia-reperfusion and severe sepsis. Though innate immunity serves a critical role in myocardial injury in response to severe sepsis and ischemia-reperfusion, the cellular and molecular mechanisms in myocardial injury in ischemia-reperfusion is complicated, involving energy metabolism disorder and free radical generation (27).

Another mechanism of myocardial sepsis is apoptosis. Growing evidence suggests that apoptotic pathways in the myocardium are activated during sepsis (28). Previous studies have suggested that TLR3-TRIF signaling mediates apoptosis in pancreatic infection, myocardial ischemia-reperfusion injury, and sepsis-induced myocardial damage $(15,29)$. TLR3-TRIF activation has been demonstrated to stimulate the extrinsic and intrinsic apoptotic pathways by upregulating TNF-related apoptosis-inducing ligand and its receptors, and downregulating the anti-apoptotic protein, B-cell lymphoma 2 (30). MyD88 signaling in myocardial apoptosis is linked closely to NF- $\kappa B$ expression; however, the relationship between cardiac $\mathrm{NF}-\kappa \mathrm{B}$ activity and apoptosis in injury remains unclear. $\mathrm{NF}-\mathrm{\kappa B}$ has proven to be detrimental in some model systems, and protective in others (13), for the secondary relation to the NF- $\kappa \mathrm{B}$ pathway promotes the transcription of pro- and anti-apoptotic proteins (31). Thus, it was concluded that, in attenuating myocardial deterioration, the inhibition of MyD88 signaling predominantly focused on reducing the inflammatory reaction. High levels of apoptotic regulatory factors, such as Fas/FasL and caspase-3, were observed in hearts from mice who received CLP in the present study. The inhibition of MyD88 and TRIF signals decreased the levels of these regulatory factors. Fas/FasL and caspase-3 levels were slightly higher in the anti-MyD88-CLP than in the anti-TRIF-CLP group; however, this difference was not significant. We speculate that the near equivalence of apoptosis regulatory factors between the anti-MyD88-CLP and anti-TRIF-CLP groups in the present study indicate that MyD88 and TRIF are both essential for severe sepsis-induced cardiac dysfunction, thus may be used as targets for treatment.

Some limitations of the present study should be noted. Firstly, the murine model of CLP induces a severe systemic inflammatory response that is often observed in the early stage of sepsis. It does not create immune suppression, which is often exhibited in patients who succumb to the chronic phase of sepsis. Therefore, the role of MyD88 and TRIF signaling in cardiac dysfunction under those conditions remains to be investigated. Secondly, the administration of anti-MyD88 and anti-TRIF antibodies in the present model did not permit the delineation of the specific roles of their upstream signaling, including TLR3 and TLR4, in mediating cardiac dysfunction. Therefore, the effect of specific TLRs in sepsis-induced cardiac dysfunction requires further research. 
In conclusion, the present study demonstrated that inhibition of MyD88 and TRIF improves survival and cardiac function in a murine model of CLP-induced severe sepsis. MyD88 and TRIF inhibition have an equivalent effect on cardiac function. MyD88 and TRIF signaling pathways may be promising targets for the treatment of severe sepsis-linked myocardial dysfunction in clinical practice.

\section{Acknowledgements}

The present study was supported by the National Natural Science Foundation of China (grant nos. 81201096 and 81503445) and Hunan Province Science and Technology program (grant nos. 2013SK3041 and 2016JJ2095).

\section{References}

1. Schefold JC, Bierbrauer J and Weber-Carstens S: Intensive care unit-acquired weakness (ICUAW) and muscle wasting in critically ill patients with severe sepsis and septic shock. J Cachexia Sarcopenia Muscle 1: 147-157, 2010.

2. No authors listed: American College of Chest Physicians/Society of Critical Care Medicine Consensus Conference: Definitions for sepsis and organ failure and guidelines for the use of innovative therapies in sepsis. Crit Care Med 20: 864-874, 1992.

3. Angus DC, Linde-Zwirble WT, Lidicker J, Clermont G, Carcillo J and Pinsky MR: Epidemiology of severe sepsis in the United States: Analysis of incidence, outcome, and associated costs of care. Crit Care Med 29: 1303-1310, 2001.

4. Parrillo JE, Parker MM, Natanson C, Suffredini AF, Danner RL, Cunnion RE and Ognibene FP: Septic shock in humans. Advances in the understanding of pathogenesis, cardiovascular dysfunction, and therapy. Ann Intern Med 113: 227-242, 1990.

5. Rudiger A and Singer M: Mechanisms of sepsis-induced cardiac dysfunction. Crit Care Med 35: 1599-1608, 2007.

6. Niu J, Azfer A and Kolattukudy PE: Protection against lipopolysaccharide-induced myocardial dysfunction in mice by cardiac-specific expression of soluble Fas. J Mol Cell Cardiol 44: 160-169, 2008.

7. Fauvel H, Marchetti $\mathrm{P}$, Chopin C, Formstecher P and Nevière R: Differential effects of caspase inhibitors on endotoxin-induced myocardial dysfunction and heart apoptosis. Am J Physiol Heart Circ Physiol 280: H1608-H1614, 2001.

8. O'Neill LA, Golenbock D and Bowie AG: The history of Toll-like receptors - redefining innate immunity. Nat Rev Immunol 13 453-460, 2013.

9. Mann DL: The emerging role of innate immunity in the heart and vascular system: For whom the cell tolls. Circ Res 108: $1133-1145,2011$.

10. Chao W: Toll-like receptor signaling: A critical modulator of cell survival and ischemic injury in the heart. Am J Physiol Heart Circ Physiol 296: H1-H12, 2009.

11. Iwasaki A and Medzhitov R: Toll-like receptor control of the adaptive immune responses. Nat Immunol 5: 987-995, 2004.

12. Takeda K, Kaisho T and Akira S: Toll-like receptors. Annu Rev Immunol 21: 335-376, 2003.

13. Weighardt H, Kaiser-Moore S, Vabulas RM, Kirschning CJ, Wagner $\mathrm{H}$ and Holzmann B: Cutting edge: Myeloid differentiation factor 88 deficiency improves resistance against sepsis caused by polymicrobial infection. J Immunol 169: 2823-2827, 2002.

14. Guidotti LG and Chisari FV: Noncytolytic control of viral infections by the innate and adaptive immune response. Annu Rev Immunol 19: 65-91, 2001.
15. Chen C, Feng Y, Zou L, Wang L, Chen HH, Cai JY, Xu JM, Sosnovik DE and Chao W: Role of extracellular RNA and TLR3-Trif signaling in myocardial ischemia-reperfusion injury. J Am Heart Assoc 3: e000683, 2014.

16. Kaczorowski DJ, Nakao A, Vallabhaneni R, Mollen KP, Sugimoto R, Kohmoto J, Zuckerbraun BS, McCurry KR and Billiar TR: Mechanisms of Toll-like receptor 4 (TLR4)-mediated inflammation after cold ischemia/reperfusion in the heart. Transplantation 87: 1455-1463, 2009.

17. Li Y, Si R, Feng Y, Chen HH, Zou L, Wang E, Zhang M, Warren HS, Sosnovik DE and Chao W: Myocardial ischemia activates an injurious innate immune signaling via cardiac heat shock protein 60 and Toll-like receptor 4. J Biol Chem 286: 31308-31319, 2011.

18. Urheim S, Edvardsen T, Torp H, Angelsen B and Smiseth OA: Myocardial strain by Doppler echocardiography. Validation of a new method to quantify regional myocardial function. Circulation 102: 1158-1164, 2000.

19. Heimdal A, Støylen A, Torp H and Skjaerpe T: Real-time strain rate imaging of the left ventricle by ultrasound. J Am Soc Echocardiogr 11: 1013-1019, 1998.

20. Cimolai MC, Alvarez S, Bode C and Bugger H: Mitochondrial mechanisms in septic cardiomyopathy. Int J Mol Sci 16: 17763-17778, 2015

21. Vinten-Johansen J: Involvement of neutrophils in the pathogenesis of lethal myocardial reperfusion injury. Cardiovasc Res 61: 481-497, 2004.

22. Castoldi A, Braga TT, Correa-Costa M, Aguiar CF, Bassi EJ, Correa-Silva R, Elias RM, Salvador F, Moraes-Vieira PM, Cenedeze MA, et al: TLR2, TLR4 and the MYD88 signaling pathway are crucial for neutrophil migration in acute kidney injury induced by sepsis. PLoS One 7: e37584, 2012.

23. Zhu X, Zhao H, Graveline AR, Buys ES, Schmidt U, Bloch KD, Rosenzweig A and Chao W: MyD88 and NOS2 are essential for Toll-like receptor 4-mediated survival effect in cardiomyocytes. Am J Physiol Heart Circ Physiol 291: H1900-H1909, 2006.

24. Alves-Filho JC, de Freitas A, Spiller F, Souto FO and Cunha FQ: The role of neutrophils in severe sepsis. Shock 30 (Suppl 1): 3-9, 2008.

25. Feng Y, Zou L, Zhang M, Li Y, Chen C and Chao W: MyD88 and Trif signaling play distinct roles in cardiac dysfunction and mortality during endotoxin shock and polymicrobial sepsis. Anesthesiology 115: 555-567, 2011.

26. Zeng X, Moore TA, Newstead MW, Deng JC, Kunkel SL, Luster AD and Standiford TJ: Interferon-inducible protein 10, but not monokine induced by gamma interferon, promotes protective type 1 immunity in murine Klebsiella pneumoniae pneumonia. Infect Immun 73: 8226-8236, 2005.

27. Soraya H, Rameshrad M, Mokarizadeh A and Garjani A: Metformin attenuates myocardial remodeling and neutrophil recruitment after myocardial infarction in rat. Bioimpacts 5: 3-8, 2015.

28. McDonald TE, Grinman MN, Carthy CM and Walley KR: Endotoxin infusion in rats induces apoptotic and survival pathways in hearts. Am J Physiol Heart Circ Physiol 279: H2053-H2061, 2000.

29. Cavassani KA, Ishii M, Wen H, Schaller MA, Lincoln PM, Lukacs NW, Hogaboam CM and Kunkel SL: TLR3 is an endogenous sensor of tissue necrosis during acute inflammatory events. J Exp Med 205: 2609-2621, 2008.

30. Sun R, Zhang Y, Lv Q, Liu B, Jin M, Zhang W, He Q, Deng M, Liu X, Li G, et al: Toll-like receptor 3 (TLR3) induces apoptosis via death receptors and mitochondria by up-regulating the transactivating p63 isoform alpha (TAP63alpha). J Biol Chem 286: 15918-15928, 2011.

31. Delhalle S, Blasius R, Dicato M and Diederich M: A beginner's guide to NF-kappaB signaling pathways. Ann NY Acad Sci 1030: $1-13,2004$. 